\title{
Desigualdades regionais em educação: potencial de convergência*
}

\author{
Marcelo Medeiros ** \\ \& Luís Felipe Batista de Oliveira***
}

\begin{abstract}
Resumo: $\mathrm{O}$ estudo analisa os fatores que afetam as desigualdades educacionais entre e dentro de regiões do Brasil. $O$ interesse é, por um lado, em como diferenças nas características das populações afetam resultados educacionais e, por outro, em como peculiaridades regionais implicam distintas respostas educacionais a essas características. Para isso é analisada a população de jovens de 14 a 17 anos em todo o Brasil, a partir de dados da Pnad 2011. Por meio da decomposição da desigualdade entre efeitos de características observadas, respostas a essas características e fatores não explicados na predição da escolaridade conclui-se que as respostas às características são mais importantes que diferenças nas distribuições de características quando o objetivo é explicar desigualdades inter e intrarregionais. Há, portanto, a possibilidade de se reverter uma parte da desigualdade educacional por meio de políticas educacionais que promovam uma convergência na direção das regiões em melhores condições.
\end{abstract}

Palavras-chave: desigualdade educacional; estratificação educacional; desigualdade regional; federalização da educação.

\section{Introdução}

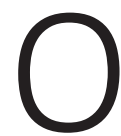
objetivo deste estudo é avaliar se a distribuição espacial de características dos indivíduos e suas famílias é um determinante importante das elevadas desigualdades regionais em educação observadas no Brasil. Dois tipos de diferença são tratadas pelo estudo. Primeiro, as diferenças na distribuição na população, de cada região, das características que, reconhecidamente, afetam a educação das crianças e dos jovens. Segundo, as diferenças regionais nos mecanismos que interagem com essas características e resultam maior ou menor nível educacional e seus efeitos para a desigualdade dentro das regiões. Ao fazer essa avaliação, o estudo pretende verificar se as desigualdades regionais em fatores não escolares que afetam a educação são um princípio de limitação importante para que políticas educacionais de convergência regional alcancem seus resultados desejados.

Nos níveis primário e secundário, a educação no Brasil é altamente descentralizada e essa descentralização se torna evidente na heterogeneidade de gastos e formas de gestão do sistema de ensino, não só entre estados como, também, entre municípios. Em larga medida, desigualdades educacionais refletem desigualdades regionais mais amplas (Castro, 2000; Rigotti, 2001) e os estados e municípios mais pobres são justamente

\footnotetext{
* Agradecemos a Sergei Soares por uma série de sugestões durante a fase de planejamento deste estudo. Agradecemos ainda os comentários dos participantes de um seminário do Instituto de Pesquisa Econômica Aplicada (Ipea), onde uma versão preliminar dos resultados deste artigo foi apresentada e discutida.

** Marcelo
Medeiros é
pesquisador do
IPEA e professor
colaborador do
Departamento
de Sociologia da
Universidade de
Brasília. <mclmdr@
unb.br>.
***Luís Felipe
Batista de Oliveira é
pesquisador do Ipea.
$<$ luis.oliveira@ipea.
gov.br>.
}


aqueles que mais deveriam elevar o nível educacional de suas populações para alcançar os patamares das áreas com melhor desempenho (Beltrão, Camarano \& Kanso, 2002).

A redução dessas desigualdades regionais é meta de várias iniciativas políticas. As propostas para enfrentar o problema variam, mas praticamente todas incluem algum grau de transferência de certas responsabilidades pelo ensino básico para o governo federal, particularmente aquelas relacionadas a seu financiamento. O que fundamenta esse argumento é a ideia de que a convergência regional não irá ocorrer espontaneamente dentro de um prazo razoável e que só o governo federal é capaz de mobilizar os recursos econômicos e políticos necessários para conduzir uma política igualitarista ativa.

A maior parte do debate sobre convergência educacional entre regiões tem foco no sistema de ensino, mais exatamente, na contratação ou qualificação de professores e, em menor escala, em infraestrutura. Expressão disso é a ênfase dada aos pisos salariais de professores e aos equipamentos escolares. Colocando de forma sintética, o debate centra-se na equiparação de escolas como mecanismo para a convergência regional. Há, evidentemente, propostas que vão além da equiparação de escolas e se preocupam com outros itens como, por exemplo, políticas de segurança escolar (Buarque, 2011). Todavia, os itens não estritamente escolares dessas propostas têm uma posição secundária nos debates públicos.

Para definir políticas de redução das desigualdades regionais importa saber quais são seus determinantes. Como a educação é uma atividade relativamente complexa e seguramente ocorre também fora do ambiente escolar, uma lista de determinantes de desigualdades educacionais pode ser bastante extensa. Uma maneira de se organizar esses determinantes é dividi-los em grupos. Um primeiro grupo pode ser denominado Escolas, e inclui, mas não se limita a, características dos professores, da administração, infraestrutura das instalações, currículos e técnicas de ensino; um segundo grupo, Ambiente social, tenta abarcar fatores não escolares da sociedade que afetam de modo relevante a educação como, por exemplo, transporte, segurança e valores culturais relacionados à educação e ao trabalho; finalmente, um terceiro grupo pode ser denominado Características individuais e familiares, o qual remete à educação dos pais, sua renda, a composição da família e atributos individuais como raça, sexo e deficiência. Trata-se de uma divisão puramente analítica, pois há alguma interseção e muita interação entre essas categorias.

Sob a ótica do desenho de políticas públicas, a divisão dos determinantes nesses três grupos faz sentido. Reformas educacionais conseguem produzir impactos fortes sobre as características das escolas e, em alguma medida, podem tornar o ambiente social mais favorável a seus objetivos, mas apenas em alguns casos têm efeitos relevantes 
sobre os determinantes individuais e familiares da educação. Estes últimos determinantes se alteram mais lentamente e o mais comum é que os resultados dessa alteração sejam observáveis entre uma geração e outra.

A maior parte da literatura sobre o Brasil e outros países argumenta que as escolas ou os fatores escolares não seriam o principal determinante da desigualdade educacional. Há bastante evidência apontando na direção de que a origem social, identificada por meio de características pessoais e familiares, possui um peso gigantesco no desempenho educacional de crianças e jovens (Albernaz, Ferreira \& Franco, 2002; Alves, Ortigão \& Franco, 2007; Alves \& Soares, 2007; Cesar \& Soares, 2001; Gonçalves \& França, 2008), de que esse peso é o que mais determina a dinâmica das desigualdades educacionais no Brasil (Silva \& Hasenbalg, 2000) e que ele aumenta com a idade das pessoas (Barros et alii, 2001).

É de se presumir, portanto, que as Características individuais e familiares são um fator de limitação importante para que políticas educacionais alcancem os resultados desejados. Se uma parte expressiva das desigualdades regionais em educação no Brasil for determinada por essas características, não se deve esperar resultados relevantes de reformas que aumentem a qualidade das escolas, ou modifiquem o ambiente social dos estudantes. Neste caso, mesmo uma completa equiparação das escolas em piores condições com as melhores escolas do Brasil seria insuficiente para assegurar a convergência entre regiões. Cabe, portanto, examinar o assunto empiricamente.

Para realizar esse exame, o estudo tem como meta mensurar o efeito da distribuição espacial das Características individuais e familiares nas desigualdades educacionais. 0 procedimento utilizado para essa mensuração consiste em estabelecer uma região de referência, estimar uma situação hipotética na qual todas as regiões teriam uma distribuição de características de Ambiente social e Escola semelhantes às da região de referência, mas manteriam suas distribuições de Características individuais e familiares tais como observadas para, então contrastar as desigualdades regionais existentes com as estimadas nessa situação hipotética. Implicitamente, o que o procedimento faz é estimar a resistência à redução das desigualdades regionais que seria causada pela inércia do peso das Características individuais e familiares na determinação dos níveis educacionais das crianças.

Mais exatamente, o procedimento estima funções de predição de educação parciais (sem variáveis de escola) para todas as regiões do Brasil e, por meio de uma decomposição de Juhn, Murphy e Pierce estima contrafactuais para essas regiões tendo os coeficientes e os resíduos da função de São Paulo como referência (Juhn, Murphy \& Pierce, 1993). As diferenças entre os contrafactuais e os observados são usadas para analisar os determinantes das desigualdades regionais e avaliar em que 
medida a convergência das características das escolas levaria à convergência educacional geral.

Os efeitos relacionados às Características individuais e familiares podem ser decompostos em dois grupos. O primeiro são as características propriamente ditas, como educação dos pais, raça etc. Estas características podem ser tratadas como atributos adscritos, isto é, como algo que não pode ser alterado ainda nesta geração de pessoas. O segundo é a resposta, em termos educacionais, dada a cada característica, ou seja, a forma como essa característica favorece ou impede a educação das crianças. Este segundo grupo pode ser alterado e nosso argumento é que parte do efeito das escolas sobre a educação manifesta-se nessa resposta. Em termos mais precisos, defendemos que, nas equações das funções de predição de educação, o efeito das escolas não se limita aos parâmetros das variáveis de Escola e alcança, também, os parâmetros das outras variáveis. Por exemplo, a forma como a origem socioeconômica das crianças afeta sua educação depende de como a escola educa essa criança.

Neste sentido, nossa argumentação é de que não apenas os efeitos de variáveis relacionadas à Escola, tais como a escolaridade dos professores ou a infraestrutura física das salas de aula estariam dentro do escopo de ação de políticas educacionais. Nossa interpretação é de que parte da resposta dada a variáveis não escolares, como raça, também pode ser alterada por essas políticas. É justamente por essa razão que abordamos o problema a partir de uma metodologia de decomposição de efeitos dos diversos componentes das funções de predição de educação.

Um exemplo análogo sobre o funcionamento do mercado de trabalho torna a ideia mais clara. Pessoas negras sistematicamente recebem salários menores que pessoas brancas com características similares. Essa resposta à raça dada pelo mercado de trabalho pode ser considerada efeito da discriminação. Políticas de regulação do mercado de trabalho não alteram a raça das pessoas, mas podem alterar a resposta do mercado à raça e impedir a discriminação. De modo similar, políticas educacionais não alteram diversas características das pessoas e seus ambientes, mas modificações nas escolas podem modificar a resposta que essas características recebem.

Nossa abordagem analítica lida com essa possibilidade ao tratar, hipoteticamente, do que aconteceria se algumas Características individuais e familiares da população de cada região fossem mantidas, mas as respostas a essas características fossem equalizadas em todo o país. Estamos, portanto, admitindo a possibilidade de que a rigidez da estrutura de estratificação educacional seja menor do que a determinada exclusivamente por variáveis educacionais: as escolas fazem a diferença à medida que regulam os mecanismos que convertem origem social em desempenho educacional. Implícita, em nosso argumento, está a ideia de que o peso da origem social é de fato gigantesco, mas 
pode ser reduzido por escolas mais eficazes, uma ideia que, de certo modo, é compartilhada pela maior parte da literatura brasileira, mas não chega a ser nela desenvolvida. Três ressalvas preliminares merecem ser feitas ainda na introdução. A primeira delas é que o estudo usa um indicador bastante limitado de educação, anos de estudo. A razão para isso é que esse é o único indicador de educação disponível para jovens que não frequentam escolas e, portanto, não realizam os testes padronizados das avaliações de proficiência. A segunda é que as simulações usadas também são limitadas pelo fato de não usarem, diretamente, variáveis escolares em suas equações, fato determinado pela indisponibilidade de dados escolares para toda a população. Finalmente, a terceira é a de que nossas interpretações se dão sobre o pressuposto de que as escolas modificam a forma como a origem social afeta a educação, mas não somos capazes de isolar o efeito puro das escolas, em parte devido à segunda limitação mencionada acima. Ainda assim acreditamos que o estudo traz resultados que merecem alguma atenção, os quais discutimos mais adiante.

\section{Estudos antecedentes}

Na sociologia, uma literatura relativamente extensa dedicou-se ao tema da educação. Em maior ou menor grau o assunto é objeto de discussão desde os clássicos e está presente nas obras de Marx, Durkheim e Weber. No entanto, é a partir da realização de levantamentos de dados sistemáticos que o campo da sociologia conhecido como estratificação educacional toma a forma atual. Embora esse seja um campo relativamente aberto, seu foco principal está nos determinantes da desigualdade educacional.

A literatura internacional sobre o assunto é ampla. Obviamente há especificidades entre países mas, em algum grau, um achado comum na literatura é de que os principais determinantes do nível educacional dos alunos estão relacionados a sua origem social. Posição de classe e educação dos pais, por exemplo, teriam mais peso sobre o nível educacional dos alunos que a infraestrutura educacional ou o grau de treinamento dos professores, mesmo quando o ensino é totalmente gratuito. Levada ao paroxismo, essa conclusão é sintetizada em uma máxima bem conhecida no campo, "a escola não importa" ("schools do not matter"), cuja implicação em termos de formulação de políticas educacionais é de que a inércia causada pela relação entre origem social e resultados educacionais deixa pouca margem de manobra para que o sistema de ensino reverta desigualdades educacionais.

Se esse argumento é válido para grupos de indivíduos, tende a também ser válido para espaços geográficos. Uma inércia semelhante à que dificultaria a convergência entre negros e brancos, ou entre pobres e ricos, limitaria a aproximação entre regiões mais ou menos educadas. Se as escolas não fazem diferença ou ao menos são pouco relevantes, a composição da população adulta seria o mais importante, causa imedia- 
ta de desigualdades educacionais entre as crianças e os jovens de várias regiões, afinal as características desses adultos determinam a origem social das crianças. Como as políticas educacionais não podem alterar essa origem social, a convergência regional, se acontecesse, seria extremamente lenta - levaria gerações para ocorrer.

Na verdade, o que fundamenta esse tipo de argumentação não permite concluir pela inviabilidade da convergência regional. Saber se a origem social é o principal determinante da estratificação educacional no Brasil é, essencialmente, um problema empírico. Saber se esse quadro pode ser revertido vai um pouco além disso. Uma coisa é identificar que as escolas, tais como são atualmente, não são capazes de compensar o peso da origem social no desempenho educacional; outra é concluir que porque hoje as escolas não revertem desigualdades, jamais poderão revertê-las a uma velocidade satisfatória. A ponte lógica entre "o que é" e "o que pode ser" depende, em parte, de como a evidência empírica é interpretada, e isso se aplica, evidentemente, aos estudos sobre o Brasil.

Estudos anteriores identificam elevadas desigualdades educacionais no Brasil, quando comparado a outros países. Waltenberg (2005), por exemplo, verifica que na distribuição de medidas de proficiência do Programa Internacional de Avaliação de Estudantes de 2000 (Pisa 2000) os estudantes classificados entre 10\% mais altos no Brasil obtiveram resultados $134 \%$ maiores em matemática e $83 \%$ maiores em leitura que os classificados entre os $10 \%$ mais baixos. Nenhum outro país do mundo apresenta desigualdades tão elevadas.

A questão que se coloca é o que determina, ao menos diretamente, desigualdades tão altas. A resposta é que essas desigualdades possuem, sim, forte relação com a origem social dos estudantes. Usando dados dos Sistemas de Avaliação da Educação Básica (Saeb) de 1999 e 2003, Albernaz, Ferreira e Franco (2002), por exemplo, concluem que uma parte muito expressiva (80\%) da desigualdade entre escolas (e não entre estudantes), medida pela variância do desempenho médio das escolas, deriva da composição social interna das escolas - dada por indicadores de origem social dos estudantes - e da seletividade de clientela das escolas - em algum grau, também associada à origem social.

A desigualdade entre escolas sequer responde pela maior parte da estratificação educacional, o que apoia o argumento de que não é a qualidade da escola o principal determinante das desigualdades entre estudantes. Em um estudo com base no Saeb 2003, Gonçalvez e França (2008) estimam que não chega a um terço a fração da desigualdade entre estudantes que poderia ser relacionada à desigualdade entre escolas. O determinante principal da desigualdade em proficiência é a origem social dos estudantes. Usando indicadores de proficiência do Saeb 1999, César e Soares 
(2001) estimaram que apenas um terço da desigualdade total entre alunos poderia ser atribuída a diferenças entre escolas de um mesmo estado; quase dois terços dessa desigualdade se daria por diferenças entre alunos de uma mesma escola. Resultados semelhantes são obtidos quando o indicador utilizado é a probabilidade de repetência (Alves, Ortigão \& Franco, 2007).

O termo "origem social" é envolvente e inclui uma série de fatores que vão desde a educação dos pais das crianças e jovens ao capital social de suas famílias. Por exemplo, Bonamino et alii (2010) mostram, usando o resultados testes na áreas de leitura do Pisa 2000 aplicados à população de estudantes com idade entre 15 e 16 anos de diversas séries, que o desempenho dos estudantes é fortemente influenciado por indicadores de recursos econômicos (posse de bens da família, status ocupacional dos pais etc.), recursos educacionais (educação dos pais) e capital social (diálogo familiar). Não só os fatores isolados mas também sua combinação é importante. Soares e Collares (2006), ao analisarem dados do Saeb 2001, indicam que existe uma interação importante dentro das várias dimensões da origem social e entre essas dimensões e outras, como as escolares, determinando o desempenho dos alunos.

As evidências, aliás, são de que a origem social cresce em importância como fator de estratificação à medida que os alunos avançam no sistema de ensino. Medindo resultados educacionais por meio de anos de estudo concluídos com aprovação, Barros et al. (2001) apresentam resultados que permitem inferir que o peso dos determinantes familiares aumenta expressivamente com a idade, um indicador indireto do progresso dos alunos no fluxo escolar.

Não há dúvida de que o peso da origem social no desempenho educacional das crianças e jovens brasileiras é muito grande. Isso significa que, para explicar as desigualdades regionais em educação, muito mais importante que as diferenças na qualidade das escolas das várias regiões são as diferenças nas populações adultas de cada região. Cabe perguntar, no entanto, se essa é uma situação reversível, ou seja, se mudanças na qualidade geral das escolas das regiões em piores condições podem contribuir para uma convergência regional acelerada.

A resposta para isso parece desanimadora. A depender de como seja feita, a elevação da qualidade geral das escolas, ou seja, um aumento de nível que beneficia igualmente todos os alunos dessas escolas, pode resultar em maior desigualdade intraescolar. Com base em um estudo longitudinal que acompanhava mudanças na qualidade das escolas e seus impactos na estratificação educacional Franco, Brooke e Alves (2008) identificaram que a melhoria na qualidade das escolas beneficia mais os alunos de nível socioeconômico mais elevado que os demais. Argumento similar é mantido por Albernaz, Ferreira e Franco (2002). 
Ao analisar o mesmo problema sob uma ótica diferente - a do impacto de gastos com educação de um município no desempenho médio das escolas desse município -, Amaral e Menezes-Filho (2008) concluem em direção semelhante, a de que um aumento dos gastos - presumivelmente indicando uma melhora na qualidade - beneficia mais os municípios em que o desempenho geral dos alunos já é superior. Não é sem razão que Silva e Hasenbalg (2000) estimam que as mudanças nas características dos pais das crianças e jovens tiveram maior importância para o aumento da escolaridade e redução da desigualdade educacional da população brasileira do que as melhorias no sistema educacional no período entre as décadas de 1970 e 1990.

Assim, uma primeira interpretação da evidência empírica dada pelos estudos acima sugere que uma expansão dos gastos ou uma elevação da qualidade dos insumos escolares (infraestrutura, professores etc.) poderia ser de pouca efetividade para reduzir desigualdades regionais e, eventualmente, ter o efeito indesejável de aumentar a desigualdade dentro das regiões. Embora essa seja uma interpretação possível, ela é contestável. Diga-se de passagem, ela é contestada, pois nenhum dos estudos acima endossa a visão de que as escolas não importam.

A maior parte dos estudos sobre determinantes da desigualdade educacional baseia-se em algum tipo de análise de regressão. Nessa análise, algumas variáveis são classificadas na categoria geral "insumos escolares" e outras na "origem social" e as regressões retornam os parâmetros que indicam o peso de cada uma das variáveis na determinação dos resultados educacionais. Um passo adicional, dado sem cautela, seria associar "insumos escolares" ao que pode ser mudado pelas políticas educacionais e "origem social" ao que não pode. Este é exatamente o passo que é disputado neste estudo. Nosso argumento é que não está ao alcance das políticas educacionais mudar características das famílias das crianças e jovens, mas é possível que essas políticas criem um sistema de ensino no qual o peso da origem social seja menor. Cabe, portanto, avaliar que evidência foi levantada por estudos anteriores que pode apoiar essa proposição.

Há indicações na direção de que o peso da origem social pode ser reduzido por um sistema de ensino. Barros et alii (2001) concluíram que características familiares são um determinante mais importante do desempenho de jovens e crianças no Nordeste em comparação ao Sudeste. Logo, há aqui um elemento importante de diferenciação entre as regiões que não diz respeito apenas às composições diferenciadas de suas populações e sim à forma como a educação responde em cada região. A desvantagem nordestina seria em parte reduzida simplesmente se a educação nordestina respondesse a características das escolas tal como ocorre no Sudeste, mesmo sem qualquer modificação na origem social dos alunos dessas regiões. 
Além disso, Soares e Sátyro (2008) mostram um efeito extremamente alto da elevação da duração dos turnos escolares na redução da defasagem idade-série das crianças, mesmo depois de controladas diversas outras variáveis. É razoável interpretar isso como indicação de que a expansão dos horários escolares na direção das escolas em tempo integral permite que a escola suplemente as deficiências das famílias, especialmente as classes muito baixas, tornando as características das famílias das crianças menos importantes do que são atualmente.

Mais ainda, no mesmo estudo, Soares e Sátyro encontram indicações de que o impacto de melhorias em variáveis escolares não é o mesmo para todos os tipos de escola e todas as crianças e jovens, resultado, aliás, que encontra equivalentes internacionais. O efeito de melhorias em infraestrutura e equipamentos pedagógicos parece ser razoável em escolas em piores condições, embora esses resultados variem conforme a técnica de análise utilizada. Se isso estiver correto - e parece estar - então algo tão elementar quanto o nivelamento de infraestrutura das escolas já pode ser um passo para a convergência regional. Esse efeito não deve ser subestimado: usando dados do Saeb 2003, Gonçalvez e França (2008) calculam que o efeito positivo de melhorias na infraestrutura escolar equivale aproximadamente ao que se observaria caso houvesse uma elevação nos gastos com educação de 1\% do PIB.

Não só infraestrutura física mas, também, aspectos organizacionais, podem modificar os pesos relativos da escola e da origem social. Na verdade, esses determinantes organizacionais, que são muito diferenciados entre regiões, podem ser muito mais importantes em um processo de convergência regional que a infraestrutura física. Processos de escolha de diretores, participação dos professores na gestão escolar, enfoque dos diretores nas atividades fim das escolas e enfoque da política educacional na educação (em contraposição à assistência social, por exemplo), têm mais peso que a infraestrutura física, depois que essa atinge um nível mínimo aceitável (Alves, 2008; Alves \& Soares, 2008).

Finalmente, uma parte importante das vantagens de certas regiões do país - como a Sudeste - está relacionada a diferenciações regionais nas redes escolares que não aparecem claramente como tais. Por exemplo, as escolas federais têm desempenho sistematicamente superior ao das escolas particulares e estas um desempenho acima do das escolas da rede pública geral (estadual e municipal). Para além do fato de que isso provavelmente possui relação com mecanismos de seletividade de clientela, deve-se notar que essa hierarquia, por um lado, indica que os diferenciais de desempenho não estão relacionados somente à gestão pública ou privada das escolas e, por outro, sugere que mudanças organizacionais aumentam o papel das escolas na educação. O estudo de caso de Rocha e Perosa (2008) em uma cidade do estado de São Paulo, por exemplo, mostra que, mesmo recebendo salários inferiores aos da rede 
pública, os professores de escolas particulares têm maior comprometimento com um plano pedagógico e se esforçam mais para criar um clima acadêmico estimulante para os estudantes que seus pares da rede pública. Como a maior parte dos alunos da rede privada vive na região Sudeste e como os custos relativos da educação privada são, para as famílias de renda baixa, o dobro do que são para as de renda alta, parte da diferenciação regional atual muito provavelmente ocorre em função de fatores organizacionais e de gestão que não são facilmente observados nos inquéritos escolares, mas que podem ser objeto de mudanças organizacionais que tenham como objetivo a convergência regional em educação.

Em termos gerais, a literatura aponta a origem social das crianças e jovens como um dos mais importantes determinantes de seu nível educacional. Há um acúmulo relativamente grande de evidências de que essa origem tem, atualmente, uma importância maior para a estratificação educacional que as características das escolas. Neste sentido, há limitações importantes para políticas de convergência regional em educação. Por outro lado, o fato de as escolas terem, hoje, um papel secundário na estratificação educacional, não significa que esse papel não pode ser mais expressivo. Não cabe discutir aqui que tipo de políticas poderiam reverter esse quadro, mas aparentemente medidas que façam com que as escolas suplementem as desvantagens de famílias de menor nível educacional, como as escolas em tempo integral, bem como medidas que aumentem a qualidade das escolas, como as relacionadas à qualificação, ao engajamento, à organização e à gestão do trabalho docente e da infraestrutura escolar, poderiam promover uma convergência regional. A questão empírica que permanece é quanta convergência se pode esperar de reformas educacionais amplas que reduzam o peso da origem social na educação, o que é objeto da discussão a seguir.

\section{Metodologia}

\section{Dados}

Foram utilizados os microdados da Pesquisa Nacional por Amostra de Domicílios (Pnad) de 2011, levada a campo em setembro daquele ano pelo Instituto Brasileiro de Geografia e Estatística (IBGE). A amostra do levantamento é desenhada para representar toda a população do Brasil. Essa amostra registra 358,9 mil indivíduos, que representam uma população total de 195,2 milhões de pessoas. É objeto do estudo apenas a população com idades entre 14 e 17 anos, o que, em termos de amostra, significam 26,5 mil registros representando uma população de 14,2 milhões pessoas. Com a eliminação de registros com dados faltantes que impossibilitariam as regressões, permaneceram na base de dados 24,9 mil registros. A escolha por um inquérito domiciliar, em contraposição a exames escolares de proficiência, deve-se ao fato de que, diferentemente dos exames escolares, a Pnad levanta também informações so- 
bre jovens que não frequentam a escola, um grupo muito importante para as políticas educacionais, em particular para políticas de redução de desigualdades regionais.

A população na Pnad foi dividida em sete unidades geográficas, baseadas na divisão em cinco Grandes Regiões normalmente utilizada pelo IBGE. Duas dessas Grandes Regiões foram subdivididas. A Região Sudeste foi subdividida em duas partes, uma denominada São Paulo (formada exclusivamente pelo estado de São Paulo) uma vez que as características de São Paulo são a base das comparações realizadas no estudo, e outra denominada Estados Sudeste (contempla os demais estados da Grande Região). Da Região Centro-Oeste foi destacado o Distrito Federal, criando assim a subdivisão denominada Estados Centro-Oeste, que reúne os estados da região excluindo o Distrito Federal, que foi tratado como região a parte. A separação foi feita para lidar mais adequadamente com a grande desigualdade na qualidade das escolas e nas características das populações do Distrito Federal e demais estados do Centro-Oeste. Desagregações mais refinadas, por unidades da federação, foram testadas, mas descartadas devido a problemas de micronumerosidade (o Amapá, por exemplo, possuiria apenas 269 casos em uma regressão com mais de 40 variáveis de controle).

\section{Procedimentos}

Os anos de estudo concluídos com aprovação das pessoas, seja em regimes com promoção automática ou regimes com promoção condicional a notas e reprovação, são o indicador educacional utilizado para as crianças e seus pais. Claramente, os anos de estudo são um indicador insuficiente da qualidade da educação, uma vez que contemplam informação muito limitada sobre o desempenho educacional dos alunos. No entanto, eles são o único indicador disponível nos dados existentes que atendem aos propósitos do estudo de levar em consideração também alunos temporariamente evadidos ou que abandonaram definitivamente a escola, o que não é possível nos dados provenientes de exames de proficiência.

O procedimento adotado consiste em três etapas. Primeiro, estimar, por regressão linear, uma função de predição de educação para cada uma das unidades geográficas. Em seguida, estimar, usando a decomposição de Juhn, Murphy e Pierce (JMP), qual seria a distribuição de anos de estudo da população caso o efeito dos determinantes (parâmetros das variáveis independentes) e a distribuição de resíduos das equações de predição de cada unidade geográfica fossem os mesmos de São Paulo (Juhn, Murphy \& Pierce, 1993). Finalmente, calcular a diferença entre os valores observados aos simulados. Para efeitos de comparação, o mesmo procedimento foi repetido, sem, porém, alterar os resíduos observados, imputando apenas os parâmetros de São Paulo. 
Na equação de regressão linear, a variável dependente é o número de anos estudo das crianças de 14 a 17 anos e as variáveis independentes são o logaritmo da renda domiciliar per capita, idade, cor (brancos e amarelos $=1$, negros $=0$ ), sexo (homem $=1$, mulher $=0$ ), número de irmãos no domicílio e dummies de escolaridade do pai e da mãe, com categorias separadas para a ausência de pai ou mãe, dummy para mãe trabalha 15 ou mais horas semanais, natureza institucional ou dependência da escola (não frequenta como base e dummies separadas de cada situação administrativa, seja a escola privada, municipal, estadual ou federal) e controle das características geográficas do local de residência (uma identificando municípios autorrepresentativos na amostra, inclusive os de regiões metropolitanas - onde os não autorrepresentativos são iguais à zero - e outra identificando zonas urbanas, com o rural igual a zero).

A distribuição de anos de estudo contrafactual de cada região é estimada por meio da decomposição proposta por Juhn, Murphy e Pierce (JMP), a qual permite isolar os efeitos de resposta (coeficientes das equações de predição), características (diferenças nos atributos das pessoas em cada região) e efeitos não explicados por regressões lineares (resíduo). Estima-se, primeiro, uma equação de predição de educação para uma região de referência (São Paulo) e, em seguida, estima-se a mesma equação para cada uma das demais regiões. A educação simulada da região de referência é calculada como sendo o número de anos de estudo obtido nessa região caso as respostas (coeficientes) e a distribuição dos efeitos não explicados (resíduo) fossem, para essa região, equivalentes aos da região de referência - ou seja, permite-se apenas a variação das características das pessoas entre regiões. De modo simplificado, porém não exato, equivale a estimar o que ocorreria caso as pessoas do Sul, por exemplo, fossem trazidas para estudar em São Paulo.

A educação contrafactual dos indivíduos foi usada não só para a decomposição JMP, mas, também, para gerar distribuições simuladas de educação. Se o sistema educacional brasileiro funcionasse sem distinção entre seus alunos as respostas implícitas (os coeficientes das regressões) seriam as mesmas em todas as regiões. Por exemplo, o fato de estudar em escolas urbanas afetaria a escolaridade de todos os alunos da mesma forma, independentemente de residirem em São Paulo ou no Nordeste. A metodologia proposta decompõe as diferenças totais em, isoladamente, a diferença devida aos atributos, aos parâmetros e aos resíduos das regressões.

Comparações regionais estão sempre sujeitas ao risco de falácia de inferência a partir de agregados ou falácia ecológica. A metodologia utilizada não permite evitá-lo completamente, mas o minimiza por dois motivos. Primeiro, depende apenas de médias condicionais, por usar regressões, e essas médias condicionais são usadas tão somente para a obtenção dos parâmetros das regressões, mantendo os atributos dos 
indivíduos tal como observados. Segundo, porque mantém a distribuição relativa de resíduos não explicados pelas regressões tal como observada, indivíduo a indivíduo, e esses resíduos são considerados nas análises das diferenças regionais.

\section{Resultados}

As diferenças regionais nas médias de anos de estudo da população brasileira de 14 a 17 anos são elevadas. Em termos absolutos, a desvantagem é maior entre os estados das regiões Norte e Nordeste. Comparadas a São Paulo, essas regiões apresentam uma defasagem média de cerca de 1,3 anos de estudo, como mostra a Tabela 1. Em relação à média de São Paulo, que é de 7,8 anos de estudo, a defasagem das regiões Norte e Nordeste é de cerca de $17 \%$. Também se observam desvantagens importantes dos demais estados da região Sudeste em relação a São Paulo, com a diferença sendo em torno de 0,8 anos de estudo. Essas desvantagens não devem ser negligenciadas. O bloco de estados mais ricos composto por Rio de Janeiro, Minas Gerais e Espírito Santo está em posição pior do que o formado por estados notadamente mais pobres como Mato Grosso, Mato Grosso do Sul, Goiás e Tocantins. Como se discutirá adiante, compondo essa desigualdade regional estão tanto diferenças de nível como de distribuição dentro de cada região.

\section{TABELA 1}

DECOMPOSIÇÃO DAS DESIGUALDADES EDUCACIONAIS REGIONAIS MÉDIAS EM RELAÇÃO A SÃO PAULO, 2011

\begin{tabular}{|c|c|c|c|c|c|c|}
\hline & $\begin{array}{l}\stackrel{ \pm}{ \pm} \\
\frac{0}{2}\end{array}$ & $\begin{array}{l}\stackrel{y}{0} \\
\frac{0}{0} \\
\frac{0}{0} \\
z\end{array}$ & 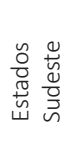 & $\bar{\Xi}$ & 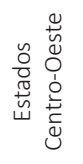 & 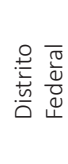 \\
\hline 1. Diferença nas características (X) & 0,43 & 0,58 & 0,18 & 0,00 & 0,06 & $-0,11$ \\
\hline 1.1. Renda & 0,15 & 0,20 & 0,05 & 0,01 & 0,02 & $-0,05$ \\
\hline 1.2. Outras características individuais e familiares & 0,18 & 0,24 & 0,06 & $-0,02$ & 0,05 & 0,00 \\
\hline 1.3. Dep. administrativa da escola & 0,12 & 0,18 & 0,07 & 0,04 & 0,00 & $-0,09$ \\
\hline 1.4. Localização geográfica & $-0,02$ & $-0,03$ & $-0,01$ & $-0,02$ & $-0,02$ & 0,03 \\
\hline 2. Diferença nas respostas (parâmetros) & 0,90 & 0,68 & 0,61 & 0,27 & 0,30 & 0,50 \\
\hline 3. Diferenças em não-observados (resíduos) & 0,00 & 0,00 & 0,00 & 0,00 & 0,00 & 0,01 \\
\hline 4. Diferença total em anos de estudo & 1,33 & 1,26 & 0,79 & 0,28 & 0,36 & 0,40 \\
\hline
\end{tabular}

Não se deve subestimar o significado educacional da defasagem de um ano de estudo concluído com aprovação. Estudos em outros países mostram que, à medida que sistemas educacionais se expandem, as desigualdades na quantidade de anos de estudo diminuem, mas as desigualdades na qualidade da educação mantém-se, refle- 
tindo a origem socioeconômica dos alunos, fenômeno conhecido como "desigualdade efetivamente mantida" (Lucas, 2001). Portanto, à medida que o sistema se expande, pequenas diferenças nas médias de anos de estudo entre populações tendem a estar associadas a desigualdades muito superiores na educação dos jovens. Se fosse possível o uso de outro indicador mais refinado, é provável que as diferenças observadas fossem de magnitude ainda maior.

A composição social das populações possui relação com as desigualdades regionais. Filhos de pais pobres, por exemplo, tendem a ter menos educação que filhos de pais ricos. Por este motivo, regiões com maior proporção de pobres tendem a ter médias educacionais mais baixas que as demais. Raciocínio análogo se aplicaria a outras características observadas dos indivíduos e suas famílias, como raça, educação dos pais etc. No entanto, nossos resultados sugerem que não é a desigualdade regional na distribuição das características dos indivíduos e das famílias e sim a desigualdade na resposta a essas características entre distintas regiões o que explica a maior parte da diferença regional em educação.

Colocando de outro modo, a maioria da desigualdade regional em educação não é determinada por distinções nas características das populações de cada região e sim pela forma diferenciada como essas características afetam a educação. Para influenciar o nível educacional dos jovens, suas Características individuais e familiares precisam ser transformadas ou convertidas em educação pela ação de algum mecanismo social. Por exemplo, ser negro, isoladamente, só resulta menos educação quando atuam mecanismos discriminatórios. A desigualdade regional está mais associada à força desses mecanismos do que a diferenças características das populações.

O efeito total da composição das características da população em cada região na defasagem em relação a São Paulo oscila bastante, mas sempre corresponde a menos da metade da diferença total. Nas regiões Nordeste e Norte, que apresentam a maior defasagem em relação a São Paulo, as características respondem por, respectivamente, $46 \%$ e $32 \%$ da defasagem. Nos estados do Sudeste, que excluem São Paulo, 23\% da defasagem; na região Sul, que possui uma composição populacional de jovens próxima à de São Paulo, apenas 1\%. O efeito maior é o da desigualdade nas respostas a essas características, que são medidas pelos parâmetros das regressões. Esse efeito responde por mais da metade da defasagem do Nordeste, dois terços da defasagem do Norte, três quartos nos estados do Sudeste e praticamente toda a defasagem do Sul.

Parte dos mecanismos que fazem com que haja respostas em termos educacionais para determinadas características dos jovens atua dentro das escolas; outra parte, porém, atua fora delas. Neste estudo, não somos capazes de distinguir cada uma dessas 
partes. O que importa, no nosso entendimento, é que mesmo a resposta a variáveis que não são tipicamente escolares - como raça - pode ser determinada pela forma como as escolas se relacionam com os alunos. Portanto, a resposta a características medidas nos parâmetros das regressões (coeficientes) pode ser compreendida como algo que pode ser modificado pelas escolas. Como as escolas provavelmente teriam capacidade de modificar apenas uma fração dessas respostas, estas devem ser vistas como um limite máximo de ação de políticas educacionais. O limite mínimo seria dado pela modificação apenas de variáveis estritamente escolares, aspecto que não é tratado em detalhe neste estudo, salvo pela consideração dos efeitos do tipo de rede de ensino frequentado pelos alunos.

A composição do sistema escolar segundo tipo de rede ou dependência administrativa das escolas - redes privada, municipal, estadual ou federal - tem peso relevante para as desigualdades regionais, mas geralmente o peso maior é o das Características individuais e familiares. O efeito da composição por dependência administrativa deve-se a dois fatores básicos, o macro e microgerenciamento das escolas e a seletividade de clientela de alunos que cada rede é capaz de determinar. O efeito agregado das Características individuais e familiares, por sua vez, deve-se a uma série de fatores, dentre eles aqueles relacionados a como a escola responde a essas características e os relacionados à educação extraescolar que ocorre nas famílias. A Tabela 1 mostra que nas regiões com as maiores defasagens, apenas os estados do Sudeste apresentam os dois pesos aproximadamente iguais.

Tudo indica que uma redução expressiva das desigualdades regionais em educação no Brasil exige uma mudança muito radical no papel que as escolas têm na educação. Atualmente, a educação escolar não é suficiente para neutralizar o peso da origem social na determinação da escolaridade dos jovens, embora diferenças em escolas pareçam afetar bastante educação. Isso se torna evidente quando se considera que renda e outras Características individuais e familiares têm, cada uma, aproximadamente o mesmo peso de dependências administrativas. Se renda for tratada como uma característica familiar adicional, então o conjunto amplo das Características individuais e familiares tem o dobro do peso das características das escolas, ao menos no que se refere aos fatores que se expressam na divisão por dependência administrativa.

Características que não foram observadas - como, por exemplo, as referentes a seus professores ou à infraestrutura de suas escolas - não aparecem como explicação relevante para as desigualdades regionais nas decomposições realizadas. Este resultado, porém, deve ser interpretado com muita cautela. É verdade que a diferença atribuível a desigualdades regionais no nível e na distribuição dos resíduos das equações de predição educacional não são expressivas. Essa conclusão, porém, baseia-se em uma análise de resíduos, que por definição englobam fatores não conhecidos ou observa- 
dos, os quais provavelmente combinam efeitos positivos e negativos sobre a educação. Não é possível, dizer com segurança, se alguns dos elementos não observados em nosso estudo têm relevância para explicar as desigualdades regionais.

Os parâmetros de resposta às características dos indivíduos e suas famílias não são importantes somente para determinar os níveis médios de escolaridade, eles também afetam a desigualdade entre os jovens. São Paulo não só tem maior nível médio de educação como, também, menor desigualdade educacional. Portanto, é provável que uma aproximação ao sistema educacional de São Paulo não reduza apenas as diferenças entre as regiões mas, também, as desigualdades dentro das regiões. Em outras palavras, se a conversão de Características individuais e familiares em educação nas diversas regiões do Brasil seguisse um padrão semelhante ao observado em São Paulo, então seria de se esperar uma redução da desigualdade interna em todas as regiões.

A Tabela 2 apresenta uma estimativa das mudanças ocorridas na desigualdade se as características da população das diversas regiões brasileiras fossem mantidas, mas a resposta a essas características fossem alteradas para aquelas observadas em São

\section{TABELA 2}

DECOMPOSIÇÃO DOS COEFICIENTES DE GINI (BRASIL, 2011)

\begin{tabular}{|c|c|c|c|c|c|}
\hline & 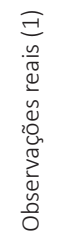 & 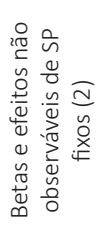 & 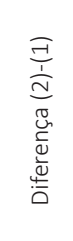 & 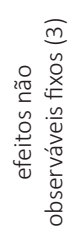 & 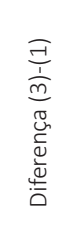 \\
\hline Norte & 0,21 & 0,15 & $-0,06$ & 0,18 & $-0,03$ \\
\hline Nordeste & 0,21 & 0,15 & $-0,06$ & 0,18 & $-0,03$ \\
\hline Sudeste sem SP & 0,17 & 0,14 & $-0,03$ & 0,16 & $-0,01$ \\
\hline São Paulo & 0,13 & - & - & - & - \\
\hline Sul & 0,14 & 0,13 & $-0,01$ & 0,14 & 0,00 \\
\hline Centro-Oeste sem DF & 0,15 & 0,13 & $-0,02$ & 0,14 & $-0,01$ \\
\hline Distrito Federal & 0,15 & 0,13 & $-0,02$ & 0,15 & 0,00 \\
\hline
\end{tabular}

Paulo. Nela é possível observar que, nas simulações, as características não observadas - os resíduos das equações - têm muito mais influência sobre a desigualdade do que sobre o nível educacional médio. Enquanto o efeito da simulação de transposição dos resíduos sobre as médias pode ser considerado irrelevante, sobre o coeficiente de Gini ele tem alguma importância, particularmente nas regiões mais desiguais. 
Nas regiões Norte, Nordeste e Sudeste sem São Paulo, as simulações sugerem que a desigualdade interna das regiões seria reduzida entre $8 \%$ e $13 \%$ caso nelas fosse observada a distribuição de resíduos de São Paulo. A magnitude do efeito, em si, não é tão relevante, porque aqui também se aplicam as ressalvas de que em uma análise de resíduos podem estar atuando forças em direções opostas. O que merece mais destaque é que o efeito conjunto da interação de fatores observados - como a qualidade das escolas, a atratividade do mercado de trabalho, entre outros - têm uma importância imediata para a desigualdade educacional que não deve ser subestimada. Métodos baseados somente em médias, como as análises de regressão comumente realizadas em estudos de estratificação educacional, tendem a negligenciar essa importância.

Efeito maior é o causado pela resposta às características observadas dos indivíduos e suas famílias, especialmente nas regiões com maior desigualdade interna. Esses efeitos respondem por entre $12 \%$ e $18 \%$ das desigualdades internas, isto é, se o processo de conversão de características em educação, em todo o Brasil, seguisse o padrão de São Paulo, a desigualdade tenderia a ser entre um décimo e um quinto menor do que a atualmente observada nas regiões Norte, Nordeste e Sudeste sem São Paulo. Estes efeitos, somados aos efeitos das variáveis não observadas, explicam até quase $30 \%$ da desigualdade interna no Norte e no Nordeste.

Os resultados obtidos para a desigualdade apontam em direções gerais similares aos resultados das simulações sobre os níveis médios: uma parte expressiva das desigualdades dentro das regiões não se deve apenas ao fato de as populações dessas regiões possuírem características desiguais, mas, também, ao fato de que a forma como essas características se converte em educação ser muito distinta. Há, evidentemente, vários fatores influenciando a conversão de atributos pessoais e familiares em educação e a escola é apenas um deles; todavia, os resultados indicam que é provável que uma convergência regional na qualidade das escolas tenha um impacto importante não somente na desigualdade entre regiões, mas também, nas desigualdades internas dessas regiões. Nossos resultados, porém, não permitem isolar adequadamente qual seria esse impacto, apenas indicar sua direção e fazer especulações sobre seus limites. Ao considerar que o efeito simulado da convergência das regiões na direção de São Paulo afeta não só o nível como também a dispersão da educação nas regiões, resta perguntar que grupos dentro de cada região seriam mais beneficiados por uma convergência desse tipo. Para isso, usamos as simulações baseadas na decomposição JMP para gerar distribuições de educação dentro de cada região. Em seguida construímos a Tabela 3 comparando os valores simulados e observados dessas distribuições.

Uma convergência regional em educação beneficiaria, principalmente, a população que hoje tem os menores níveis educacionais. No caso das regiões com maiores 
TABELA 3

VARIAÇÃO RELATIVA DE EDUCAÇÃO

POR DÉCIMOS DE ANOS DE ESTUDO ACUMULADOS (SIMULADO/OBSERVADO)

\begin{tabular}{|c|c|c|c|c|c|c|}
\hline 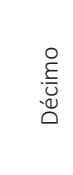 & $\begin{array}{l}\stackrel{0}{ \pm} \\
\frac{0}{2}\end{array}$ & 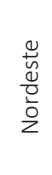 & 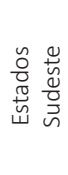 & $\overline{\bar{n}}$ & 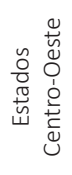 & 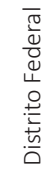 \\
\hline $10 \%$ & $121 \%$ & $93 \%$ & $44 \%$ & $4 \%$ & $21 \%$ & $25 \%$ \\
\hline $20 \%$ & $45 \%$ & $35 \%$ & $24 \%$ & $5 \%$ & $10 \%$ & $15 \%$ \\
\hline $30 \%$ & $36 \%$ & $23 \%$ & $14 \%$ & $3 \%$ & $6 \%$ & $12 \%$ \\
\hline $40 \%$ & $14 \%$ & $13 \%$ & $7 \%$ & $2 \%$ & $2 \%$ & $6 \%$ \\
\hline $50 \%$ & $10 \%$ & $7 \%$ & $9 \%$ & $4 \%$ & $5 \%$ & $8 \%$ \\
\hline $60 \%$ & $11 \%$ & $8 \%$ & $5 \%$ & $2 \%$ & $1 \%$ & $4 \%$ \\
\hline $70 \%$ & $2 \%$ & $0 \%$ & $5 \%$ & $11 \%$ & $5 \%$ & $6 \%$ \\
\hline $80 \%$ & $9 \%$ & $7 \%$ & $4 \%$ & $1 \%$ & $1 \%$ & $2 \%$ \\
\hline $90 \%$ & $2 \%$ & $2 \%$ & $5 \%$ & $4 \%$ & $2 \%$ & $5 \%$ \\
\hline $100 \%$ & $0 \%$ & $1 \%$ & $3 \%$ & $4 \%$ & $2 \%$ & $3 \%$ \\
\hline
\end{tabular}

Fonte: Microdados da Pnad 2011, IBGE.

níveis de desigualdade - Norte e Nordeste -, a elevação dos níveis educacionais do quinto inferior da distribuição seria muito expressiva. A elevação generalizada das pessoas na base da distribuição faria com que os níveis de desigualdade internos de cada região, apontados na Tabela 2, caíssem. Além disso, a melhora contribuiria para o aumento das médias de cada região apresentadas na Tabela 1 e, portanto, para a redução das desigualdades regionais em educação. Caso fosse possível fazer com que a relação entre as Características individuais e familiares dos jovens e sua educação em todo o Brasil fosse a mesma de São Paulo, seriam menores tanto os níveis de desigualdade entre as regiões como os níveis de desigualdade internos de cada região.

\section{Conclusão}

Há desigualdades regionais importantes nas médias de anos de estudo da população brasileira de 14 a 17 anos. O estado de São Paulo é a região com médias mais altas e as regiões com maior desvantagem são Norte, Nordeste e, em menor grau, os demais estados da região Sudeste. Além de uma marcada desigualdade entre regiões observa-se no Brasil, inclusive em São Paulo, níveis relativamente altos de desigualdade dentro das regiões. Esses níveis altos de desigualdade em anos de estudo chamam ainda mais a atenção porque pequenas diferenças em quantidade de educação geralmente estão associadas a diferenças maiores na qualidade dessa educação. 
Parte das desigualdades regionais pode ser explicada pela composição social das populações de cada região. Como a origem social afeta muito o nível educacional dos jovens, regiões com maiores proporções de pessoas vindas de famílias com características desvantajosas tendem a apresentar menores níveis educacionais. Todavia, nossos resultados sugerem que o que mais diferencia as regiões não é a desigualdade regional na distribuição das características dos indivíduos e das famílias, mas sim a forma diferenciada de como essas características afetam a educação em cada região. Diferenças nas respostas a características, observadas nos parâmetros das regressões das funções de predição educacional, explicam mais da metade da defasagem do Nordeste, dois terços da defasagem do Norte, três quartos nos Estados do Sudeste e quase toda a defasagem do Sul.

Além de ser o mais importante determinante da desigualdade entre regiões, a resposta às características dos indivíduos e suas famílias é também o mais importante determinante das desigualdades dentro das regiões. Se a relação entre características e escolaridade em todo o Brasil seguisse o padrão de São Paulo, a desigualdade seria entre um décimo e um quinto menor do que a atualmente observada nas regiões Norte, Nordeste e Sudeste sem São Paulo. Estes efeitos, somados aos efeitos de variáveis não observadas, explicam até quase um terço da desigualdade interna no Norte e no Nordeste.

É muito provável que parte da diferença nas respostas, mas não toda, esteja associada a diferenças nas escolas de cada região; parte pode estar relacionada a diferenças mais amplas relacionadas à educação como, por exemplo, acessibilidade, valores culturais ou atratividade do mercado de trabalho. Seguramente haverá uma parte que não tem relação com o sistema educacional. Nosso estudo não explora os determinantes das diferenças nos parâmetros das funções de predição e, portanto, não permite fazer qualquer afirmação mais específica sobre o assunto.

Uma convergência regional na direção de São Paulo beneficiaria, principalmente, a população de menor nível educacional. Se a forma como a educação em cada região se relaciona às Características Individuais e Familiares dos jovens em todo o Brasil fosse a mesma de São Paulo, cairiam os níveis de desigualdade entre as regiões e os níveis de desigualdade internos de cada região. Isso tenderia a ocorrer em função apenas de modificações nas respostas às características, ou seja, em decorrência da forma como esses atributos se convertem em educação, mesmo que os atributos atuais das populações não fossem alterados.

É provável que estas conclusões gerais se mantenham caso, no lugar de anos de estudo, um indicador mais refinado de educação fosse utilizado. O uso de outro indicador seguramente implicaria valores distintos das mudanças observadas, mas não há razão 
para crer que a direção dessas mudanças seria oposta à discutida neste estudo. De todo modo, seria útil replicar este estudo usando medidas as mais refinadas de desempenho que se obtém com testes padronizados, ainda que com o ônus de omitir da análise a população que não frequenta escolas. Além disso, o uso de dados provenientes desses testes permitiria ainda construir as funções de predição levando-se em conta variáveis referentes às características mais detalhadas das escolas, o que seguramente adicionaria informação relevante às conclusões.

No curto prazo, o sistema escolar não é capaz de mudar atributos adscritos das pessoas e suas famílias, mas pode, sim, alterar a forma como essas características afetam a educação, ou seja, a resposta, em termos de educação, a uma dada característica. Todavia, ao se interpretar os resultados obtidos não se deve perder de vista que é muito provável que uma parte dessa resposta não possa ser alterada pelo sistema educacional. Educação certamente não é uma panaceia para problemas de mobilidade social. Os resultados aqui apresentados devem, portanto, ser entendidos como um limite superior do que poderia acontecer com a educação sob a hipótese de uma convergência regional em um futuro relativamente próximo. Com as informações que dispomos, não seria prudente arriscar uma estimativa mais precisa desses efeitos.

Em termos de implicações para políticas educacionais, o estudo sugere que sem a atuação de mecanismos capazes de reduzir radicalmente o peso da origem social na educação dos jovens não é de se esperar uma redução das desigualdades regionais em educação, bem como nas desigualdades internas de cada região. Há discussões sobre várias medidas possíveis para isso, tais como alongamento dos anos letivos e educação em tempo integral (duplo turno). Nossos resultados não permitem especular sobre quais devem ser essas medidas, porém é possível afirmar com segurança que, tal como se encontra hoje, o sistema educacional tem capacidades mínimas para reduzir a vinculação entre origem e destino em uma sociedade altamente estratificada.

Se por um lado pode soar óbvio dizer que há chances ínfimas de uma convergência regional em educação aceitável sem uma melhora muito expressiva nos sistemas educacionais das regiões defasadas, por outro os resultados deste estudo indicam que um grau não desprezível de convergência pode ser obtido por uma melhora nesses sistemas.

Abstract: We analyze the factors determining educational inequalities within and between regions in Brazil. We are interested in how characteristics and the return to these characteristics in each region affect educational outcomes. For this we analyze the population of people aged 14 to 17 years in Brazil using Pnad 2011 data. By decomposing inequality in the effect of observed attributes, return to these attributes and residuals from the linear regressions used for prediction, we conclude that 
differences in the returns to the attributes are more important to inequality than differences in the distributions of attributes. Therefore, it is possible to reduce at least part of regional inequalities by means of educational policies if education in the worst off regions improves in the direction of the better off regions.

Keywords: educational inequality; educational stratification; regional inequality; federalization of education.

\section{Referências}

Albernaz; Ferreira, F. H. G.; Franco, C. Qualidade e equidade no ensino fundamental brasileiro. Pesquisa e Planejamento Econômico, v. 32, n. 3. Dez. 2002, p. 453-476.

AlVES, F. Políticas educacionais e desempenho escolar nas capitais brasileiras. Cadernos de Pesquisa, v. 38, n. 134. 2008, p. 413-440.

Alves, F.; Ortigão, I.; Franco, C. Origem social e risco de repetência: interação raça-capital econômico. Cadernos de Pesquisa, v. 37. Abr. 2007, p. 161-180.

Alves, M. T. G.; SOARES, J. F. As pesquisas sobre o efeito das escolas: contribuições metodológicas para a sociologia da educação. Sociedade e Estado, v. 22, n. 2. 2007, p. 435-473.

- O efeito das escolas no aprendizado dos alunos: um. Educação e Pesquisa, v. 34 , n. 3. 2008, p. 527-544.

Amaral; Menezes-Filho, N. A relação entre gastos educacionais e desempenho escolar. Anais do XXXVI Encontro Nacional de Economia. Anais... Salvador: Associação Nacional dos Centros de Pós-Graduação em Economia (Anpec), 2008.

BARros et alii. Os determinantes do desempenho educacional no Brasil. Pesquisa e Planejamento Econômico, v. 31, n. 1. Abr. 2001, p. 1-42.

Beltrão; Camarano, A. A.; KAnso, S. Ensino fundamental: diferenças regionais. Revista Brasileira de Estudos de População, v. 19, n. 2. 2002, p. 135-157.

BONAMINO et alii. Os efeitos das diferentes formas de capital no desempenho escolar: um estudo à luz de Bourdieu e de Coleman. Revista Brasileira de Educação, v. 15, n. 45. 2010, p. 487.

BUARQUE. A revolução republicana na educação: ensino de qualidade para todos. São Paulo: Moderna, 2011.

CASTRO. As desigualdades regionais no sistema educacional brasileiro. In: Desigualdade e pobreza no Brasil. Rio De Janeiro: Ipea, 2000, p. 425-458. 
CESAR; SOARES, J. F. Desigualdades acadêmicas induzidas pelo contexto escolar. Revista Brasileira de Estudos de População, v. 18, n. 1/2. Jan. 2001, p. 97-110.

Franco; Brooke, N.; Alves, F. Estudo longitudinal sobre qualidade e equidade no ensino fundamental brasileiro (Geres 2005). Ensaio: Avaliação e Políticas Públicas em Educação, v. 16, n. 61. 2008, p. 625-638.

GONÇALVES; FrANÇA, M. T. A. Transmissão intergeracional de desigualdade e qualidade educacional: avaliando o sistema educacional brasileiro a partir do Saeb 2003. Ensaio: Avaliação e Políticas Públicas em Educação, v. 16. Dez. 2008, p. 639-662.

JUHn; MURPhY, K. M.; PIERCE, B. Wage inequality and the rise in returns to skill. Journal of political Economy, v. 101, n. 3. 1993, p. 410-442.

LUCAS. Effectively maintained inequality: education transitions, track mobility, and social background effects. American Journal of Sociology, v. 106, n. 6. Mai. 2001, p. 1642-1690.

RigotTI. A transição da escolaridade no Brasil e as desigualdades regionais. Revista Brasileira de Estudos de População, v. 18, n. 1/2. 2001, p. 59-73.

RochA; Perosa, G. S. Notas etnográficas sobre a desigualdade educacional Brasileira. Educação e Sociedade, v. 29, n. 103. 2008, p. 425-449.

Silva; Hasenbalg, C. Tendências da desigualdade educacional no Brasil. Dados, v. 43. 2000, p. 423-445.

SoARes, J. F.; Collares, A. C. M. Recursos familiares e o desempenho cognitivo dos alunos do ensino básico brasileiro. Dados, v. 49, n. 3. 2006, p. 1-23.

SOARES, S.; SÁTYRO, N. O impacto da infraestrutura escolar na taxa de distorção idade-série das escolas brasileiras de ensino fundamental - 1998 a 2005. Brasília: MEC;Inep, 2008.

WAltenberg. Iniquidade educacional no Brasil. Uma avaliação com dados do Pisa 2000. Revista Economia, v. 6, n. 1. Jul. 2005, p. 67-118. 


\section{Anexo}

\begin{tabular}{|c|c|c|c|c|c|c|c|}
\hline Variáveis & Norte & Nordeste & $\begin{array}{l}\text { SE sem } \\
\text { São Paulo }\end{array}$ & São Paulo & Sul & $\begin{array}{c}\text { C-O sem } \\
\text { DF }\end{array}$ & $\begin{array}{l}\text { Distrito } \\
\text { Federal }\end{array}$ \\
\hline \multirow{2}{*}{$\begin{array}{l}\text { In(renda domiciliar per } \\
\text { capita) }\end{array}$} & $0.185^{* * *}$ & $0.118^{* * *}$ & $0.249 * * *$ & $0.222 * * *$ & $0.209 * * *$ & $0.201^{* * *}$ & $0.236 * * *$ \\
\hline & (0.0310) & $(0.0245)$ & $(0.0341)$ & $(0.0377)$ & $(0.0306)$ & $(0.0468)$ & $(0.0726)$ \\
\hline \multirow{2}{*}{$\begin{array}{l}\text { Mãe trabalha mais } \\
\text { de } 15 \mathrm{~h}\end{array}$} & -0.161 & -0.494 & -0.388 & -0.789 & -0.0137 & 0.462 & \\
\hline & $(0.790)$ & $(0.570)$ & $(0.816)$ & $(0.817)$ & $(0.475)$ & $(0.877)$ & \\
\hline \multirow{2}{*}{ Idade } & $0.718^{* * *}$ & $0.681^{* * *}$ & $0.841 * * *$ & $0.867 * * *$ & $0.764 * * *$ & $0.751 * * *$ & $1.055^{* * *}$ \\
\hline & $(0.0270)$ & $(0.0213)$ & (0.0269) & $(0.0323)$ & $(0.0248)$ & $(0.0376)$ & $(0.0645)$ \\
\hline \multirow{2}{*}{ Homem } & $-0.611^{* * *}$ & $-0.755^{* * *}$ & $-0.542^{* * *}$ & $-0.250^{* * *}$ & $-0.569^{* * *}$ & $-0.492^{* * *}$ & $-0.380 * * *$ \\
\hline & (0.0579) & $(0.0449)$ & $(0.0564)$ & $(0.0689)$ & $(0.0522)$ & $(0.0795)$ & $(0.140)$ \\
\hline \multirow{2}{*}{ Branco ou amarelo } & 0.00922 & $0.141^{* * *}$ & $0.159 * * *$ & $0.130^{*}$ & $0.171^{* * *}$ & 0.0384 & 0.180 \\
\hline & $(0.0700)$ & (0.0509) & (0.0598) & $(0.0718)$ & $(0.0619)$ & $(0.0830)$ & $(0.154)$ \\
\hline \multirow{2}{*}{ Número de irmãos } & $-0.118^{* * *}$ & $-0.0551^{* *}$ & $-0.149 * * *$ & $-0.165^{* * *}$ & $-0.105^{* * *}$ & -0.0290 & -0.0693 \\
\hline & $(0.0276)$ & $(0.0226)$ & $(0.0332)$ & $(0.0415)$ & $(0.0288)$ & $(0.0502)$ & $(0.0741)$ \\
\hline \multirow{2}{*}{ Pai estudou 1 ano } & 0.121 & $0.310^{* *}$ & 0.151 & 0.306 & 0.255 & 0.551 & 1.558 \\
\hline & $(0.186)$ & (0.135) & (0.209) & (0.544) & $(0.217)$ & $(0.337)$ & (1.616) \\
\hline \multirow{2}{*}{ Pai estudou 2 anos } & 0.0736 & $0.414^{* * *}$ & 0.151 & 0.0334 & -0.285 & 0.293 & -0.271 \\
\hline & $(0.144)$ & $(0.111)$ & (0.178) & $(0.238)$ & $(0.188)$ & $(0.268)$ & $(0.682)$ \\
\hline \multirow{2}{*}{ Pai estudou 3 anos } & 0.0620 & $0.202^{*}$ & $0.530 * * *$ & -0.121 & 0.188 & $-0.435^{*}$ & -0.225 \\
\hline & $(0.125)$ & (0.108) & $(0.147)$ & $(0.243)$ & $(0.146)$ & $(0.249)$ & (0.512) \\
\hline \multirow{2}{*}{ Pai estudou 4 anos } & $0.210^{*}$ & $0.388^{* * *}$ & $0.249 * *$ & $0.288^{* *}$ & $0.248^{* * *}$ & 0.193 & 0.508 \\
\hline & (0.109) & $(0.0915)$ & $(0.0983)$ & (0.138) & $(0.0925)$ & $(0.152)$ & (0.321) \\
\hline \multirow{2}{*}{ Pai estudou 5 anos } & $0.336^{* *}$ & $0.469 * * *$ & -0.0420 & 0.259 & 0.0956 & $0.367^{* *}$ & $-0.906^{* *}$ \\
\hline & $(0.137)$ & $(0.112)$ & $(0.135)$ & $(0.187)$ & $(0.110)$ & $(0.175)$ & $(0.437)$ \\
\hline \multirow{2}{*}{ Pai estudou 6 anos } & 0.0905 & 0.113 & -0.0194 & $0.595^{* * *}$ & 0.0778 & 0.212 & 0.653 \\
\hline & $(0.186)$ & $(0.165)$ & (0.178) & $(0.215)$ & $(0.154)$ & $(0.234)$ & (0.440) \\
\hline \multirow{2}{*}{ Pai estudou 7 anos } & $0.445^{* *}$ & $0.296^{* *}$ & $0.342^{* *}$ & 0.313 & $0.240^{*}$ & 0.186 & -0.0822 \\
\hline & $(0.180)$ & $(0.141)$ & $(0.158)$ & (0.195) & $(0.143)$ & $(0.211)$ & $(0.451)$ \\
\hline \multirow{2}{*}{ Pai estudou 8 anos } & $0.367^{* * *}$ & $0.428^{* * *}$ & $0.202^{*}$ & 0.197 & $0.196^{* *}$ & 0.0859 & $-0.520 *$ \\
\hline & $(0.115)$ & $(0.0980)$ & (0.108) & (0.120) & $(0.0937)$ & $(0.141)$ & $(0.268)$ \\
\hline \multirow{2}{*}{ Pai estudou 9 anos } & 0.216 & 0.130 & 0.128 & 0.267 & 0.247 & $0.627^{* *}$ & -0.748 \\
\hline & $(0.213)$ & $(0.200)$ & (0.227) & (0.251) & $(0.217)$ & $(0.266)$ & $(0.666)$ \\
\hline \multirow{2}{*}{ Pai estudou 10 anos } & $0.822^{* * *}$ & 8 & 0.201 & 0.306 & $0.521 * * *$ & 0.254 & $-1.165^{*}$ \\
\hline & $(0.217)$ & $(0.205)$ & $(0.218)$ & $(0.260)$ & (0.189) & $(0.266)$ & (0.595) \\
\hline \multirow{2}{*}{ Pai estudou 11 anos } & $0.400 * * *$ & $0.611^{* * *}$ & $0.425^{* * *}$ & $0.284^{* * *}$ & $0.416 * * *$ & $0.217^{*}$ & 0.185 \\
\hline & (0.101) & $(0.0836)$ & (0.0938) & $(0.100)$ & $(0.0864)$ & $(0.127)$ & $(0.201)$ \\
\hline \multirow{2}{*}{ Pai estudou 12 anos } & 0.362 & $1.067^{* * *}$ & 0.531 & 0.280 & 0.0907 & 0.755 & -0.418 \\
\hline & $(0.341)$ & $(0.300)$ & $(0.347)$ & $(0.377)$ & $(0.222)$ & $(0.530)$ & (0.679) \\
\hline
\end{tabular}




\begin{tabular}{|c|c|c|c|c|c|c|c|}
\hline Variáveis & Norte & Nordeste & $\begin{array}{l}\text { SE sem } \\
\text { São Paulo }\end{array}$ & São Paulo & Sul & $\begin{array}{l}\text { C-O sem } \\
\text { DF }\end{array}$ & $\begin{array}{l}\text { Distrito } \\
\text { Federal }\end{array}$ \\
\hline \multirow{2}{*}{ Pai estudou 13 anos } & $1.000 *$ & 0.452 & 0.346 & 0.409 & -0.154 & -0.293 & -0.325 \\
\hline & $(0.605)$ & $(0.424)$ & $(0.406)$ & $(0.430)$ & (0.299) & $(0.666)$ & (0.814) \\
\hline \multirow{2}{*}{ Pai estudou 14 anos } & 0.626 & 0.681 & $0.680^{*}$ & 0.0450 & 0.177 & 0.279 & 0.0507 \\
\hline & $(0.407)$ & $(0.464)$ & $(0.364)$ & $(0.402)$ & $(0.263)$ & $(0.495)$ & $(0.647)$ \\
\hline \multirow{2}{*}{ Pai estudou 15 anos } & $0.630 * * *$ & $0.895^{* * *}$ & 0.149 & 0.226 & $0.358^{* * *}$ & $0.353^{*}$ & 0.178 \\
\hline & $(0.177)$ & $(0.162)$ & (0.148) & $(0.165)$ & $(0.132)$ & $(0.214)$ & $(0.283)$ \\
\hline \multirow{2}{*}{ Mãe estudou 1 ano } & 0.0394 & $0.240 *$ & -0.0420 & 0.0445 & 0.00354 & -0.392 & -0.0958 \\
\hline & $(0.185)$ & $(0.136)$ & $(0.229)$ & $(0.368)$ & $(0.207)$ & $(0.339)$ & $(0.772)$ \\
\hline \multirow{2}{*}{ Mãe estudou 2 anos } & $0.245^{*}$ & 0.0434 & -0.0967 & -0.339 & -0.0355 & $-0.618 * *$ & 0.433 \\
\hline & $(0.142)$ & (0.115) & $(0.170)$ & (0.249) & $(0.186)$ & $(0.248)$ & (0.563) \\
\hline \multirow{2}{*}{ Mãe estudou 3 anos } & $0.388^{* * *}$ & $0.269 * * *$ & $0.426 * * *$ & -0.0959 & $0.271^{*}$ & 0.314 & $0.833^{*}$ \\
\hline & $(0.136)$ & (0.0991) & $(0.157)$ & $(0.233)$ & $(0.144)$ & $(0.240)$ & $(0.472)$ \\
\hline \multirow{2}{*}{ Mãe estudou 4 anos } & $0.429 * * *$ & $0.346^{* * *}$ & $0.431^{* * *}$ & 0.111 & $0.271^{* *}$ & 0.284 & $0.604^{*}$ \\
\hline & $(0.116)$ & $(0.0822)$ & $(0.110)$ & (0.149) & $(0.107)$ & (0.178) & $(0.320)$ \\
\hline \multirow{2}{*}{ Mãe estudou 5 anos } & $0.547^{* * *}$ & $0.443^{* * *}$ & $0.311^{* *}$ & 0.00707 & $0.279 * *$ & 0.234 & 0.520 \\
\hline & $(0.134)$ & $(0.101)$ & $(0.134)$ & $(0.178)$ & $(0.120)$ & $(0.187)$ & (0.379) \\
\hline \multirow{2}{*}{ Mãe estudou 6 anos } & $0.557^{* * *}$ & $0.324 * *$ & 0.153 & 0.201 & -0.00914 & 0.131 & $0.660^{*}$ \\
\hline & $(0.181)$ & $(0.132)$ & (0.155) & $(0.212)$ & $(0.150)$ & $(0.220)$ & $(0.400)$ \\
\hline \multirow{2}{*}{ Mãe estudou 7 anos } & $0.853^{* * *}$ & $0.735^{* * *}$ & 0.240 & 0.117 & $0.352^{* *}$ & $0.622 * * *$ & $1.313^{* * *}$ \\
\hline & $(0.148)$ & $(0.125)$ & $(0.152)$ & $(0.187)$ & (0.138) & (0.193) & $(0.470)$ \\
\hline \multirow{2}{*}{ Mãe estudou 8 anos } & $0.817^{* * *}$ & $0.876^{* * *}$ & $0.504^{* * *}$ & 0.207 & $0.441 * * *$ & $0.690 * * *$ & $1.169 * * *$ \\
\hline & (0.119) & (0.0906) & (0.113) & $(0.138)$ & $(0.107)$ & $(0.153)$ & (0.310) \\
\hline \multirow{2}{*}{ Mãe estudou 9 anos } & $0.564^{* * *}$ & $0.851^{* * *}$ & $0.837^{* * *}$ & $0.749 * * *$ & $0.602^{* * *}$ & $1.150^{* * *}$ & 0.333 \\
\hline & $(0.201)$ & (0.175) & $(0.203)$ & $(0.231)$ & $(0.187)$ & $(0.246)$ & $(0.495)$ \\
\hline \multirow{2}{*}{ Mãe estudou 10 anos } & $0.890^{* * *}$ & $0.884^{* * *}$ & 0.187 & 0.234 & $0.595^{* * *}$ & $0.851^{* * *}$ & $1.282^{* *}$ \\
\hline & $(0.205)$ & $(0.165)$ & $(0.204)$ & $(0.227)$ & $(0.180)$ & $(0.227)$ & $(0.510)$ \\
\hline \multirow{2}{*}{ Mãe estudou 11 anos } & $1.005^{* * *}$ & $1.017^{* * *}$ & $0.827 * * *$ & $0.351^{* * *}$ & $0.721^{* * *}$ & $1.115^{* * *}$ & $0.788^{* * *}$ \\
\hline & $(0.0974)$ & $(0.0794)$ & $(0.106)$ & (0.129) & (0.104) & $(0.145)$ & $(0.245)$ \\
\hline \multirow{2}{*}{ Mãe estudou 12 anos } & $1.241^{* * *}$ & $0.865^{* * *}$ & $0.475^{* *}$ & $0.589 *$ & $0.814^{* * *}$ & $1.030^{* * *}$ & 0.262 \\
\hline & $(0.241)$ & (0.229) & $(0.233)$ & (0.339) & $(0.190)$ & $(0.394)$ & $(0.585)$ \\
\hline \multirow{2}{*}{ Mãe estudou 13 anos } & $1.348^{* * *}$ & $1.284^{* * *}$ & $0.540 *$ & 0.370 & $1.056^{* * *}$ & $1.265^{* * *}$ & 0.517 \\
\hline & $(0.303)$ & $(0.307)$ & (0.301) & $(0.363)$ & (0.294) & (0.398) & (0.690) \\
\hline \multirow{2}{*}{ Mãe estudou 14 anos } & $1.268^{* * *}$ & $1.376^{* * *}$ & $0.756^{* * *}$ & 0.341 & $0.463^{* *}$ & $1.100^{* * *}$ & $1.448^{* *}$ \\
\hline & $(0.257)$ & (0.271) & $(0.262)$ & $(0.287)$ & (0.219) & (0.308) & $(0.580)$ \\
\hline \multirow{2}{*}{ Mãe estudou 15 anos } & $1.433^{* * *}$ & $0.927^{* * *}$ & $0.840 * * *$ & $0.393^{* *}$ & $0.700^{* * *}$ & $1.018^{* * *}$ & $0.790^{* *}$ \\
\hline & $(0.150)$ & $(0.127)$ & (0.148) & $(0.180)$ & $(0.135)$ & (0.191) & $(0.320)$ \\
\hline \multirow{2}{*}{ Sem mãe no domicilio } & $-0.137^{*}$ & $-0.182^{* * *}$ & -0.143 & $-0.288 * *$ & -0.122 & 0.0258 & -0.318 \\
\hline & $(0.0830)$ & $(0.0690)$ & (0.0995) & $(0.130)$ & $(0.0886)$ & (0.134) & $(0.261)$ \\
\hline
\end{tabular}




\begin{tabular}{|c|c|c|c|c|c|c|c|}
\hline Variáveis & Norte & Nordeste & $\begin{array}{l}\text { SE sem } \\
\text { São Paulo }\end{array}$ & São Paulo & Sul & $\begin{array}{c}\text { C-O sem } \\
\text { DF }\end{array}$ & $\begin{array}{l}\text { Distrito } \\
\text { Federal }\end{array}$ \\
\hline \multirow{2}{*}{ Chefe não é o pai } & -0.0110 & -0.0351 & $-0.301^{* *}$ & -0.281 & -0.0672 & -0.0144 & 0.537 \\
\hline & $(0.120)$ & $(0.0963)$ & $(0.136)$ & $(0.175)$ & $(0.115)$ & $(0.173)$ & $(0.375)$ \\
\hline \multirow{2}{*}{ Particular } & $2.557^{* * *}$ & $2.210 * * *$ & $1.427^{* * *}$ & $0.883^{* * *}$ & $1.447^{* * *}$ & $1.107^{* * *}$ & $1.307^{* * *}$ \\
\hline & $(0.164)$ & $(0.112)$ & (0.139) & (0.158) & $(0.121)$ & $(0.196)$ & $(0.352)$ \\
\hline \multirow{2}{*}{ Municipal } & $0.875^{* * *}$ & $0.860 * * *$ & $0.284^{* * *}$ & $0.268 *$ & $0.270^{* * *}$ & 0.199 & $1.049 * *$ \\
\hline & $(0.0997)$ & $(0.0760)$ & $(0.107)$ & $(0.145)$ & $(0.101)$ & $(0.166)$ & $(0.411)$ \\
\hline \multirow{2}{*}{ Estadual } & $2.216^{* * *}$ & $2.126^{* * *}$ & $1.379 * * *$ & $1.041^{* * *}$ & $1.123^{* * *}$ & $1.036^{* * *}$ & $0.748 * * *$ \\
\hline & (0.0903) & (0.0723) & (0.0936) & (0.113) & $(0.0814)$ & $(0.130)$ & $(0.275)$ \\
\hline \multirow{2}{*}{ Federal } & $2.899 * * *$ & $2.525^{* * *}$ & $1.683^{* * *}$ & $1.060^{*}$ & $1.883^{* * *}$ & $2.087 * * *$ & $1.529 * * *$ \\
\hline & $(0.306)$ & $(0.246)$ & $(0.269)$ & $(0.581)$ & $(0.285)$ & $(0.418)$ & $(0.471)$ \\
\hline \multirow{2}{*}{$\begin{array}{l}\text { RM ou } \\
\text { autorepresentativo }\end{array}$} & 0.00745 & $-0.164 * * *$ & $-0.117^{*}$ & -0.101 & $-0.175^{* * *}$ & $0.180 * *$ & \\
\hline & $(0.0642)$ & $(0.0524)$ & $(0.0630)$ & $(0.0768)$ & $(0.0546)$ & $(0.0851)$ & \\
\hline \multirow{2}{*}{ Urbana } & $0.130 *$ & 0.00729 & -0.0108 & -0.000793 & $-0.254^{* * *}$ & $-0.258 *$ & 0.499 \\
\hline & $(0.0735)$ & $(0.0554)$ & $(0.0963)$ & (0.198) & $(0.0754)$ & (0.135) & $(0.445)$ \\
\hline \multirow{2}{*}{ Constante } & $-7.701 * * *$ & $-6.228 * * *$ & $-8.676 * * *$ & $-7.907 * * *$ & $-6.512 * * *$ & $-6.559 * * *$ & $-12.29 * * *$ \\
\hline & (0.469) & $(0.370)$ & $(0.482)$ & $(0.605)$ & $(0.444)$ & $(0.678)$ & (1.195) \\
\hline $\begin{array}{l}\text { Número de } \\
\text { observações }\end{array}$ & 4,587 & 7,822 & 4,036 & 2,241 & 3,725 & 1,952 & 546 \\
\hline$R^{2}$ & 0.382 & 0.355 & 0.366 & 0.335 & 0.359 & 0.336 & 0.458 \\
\hline
\end{tabular}


